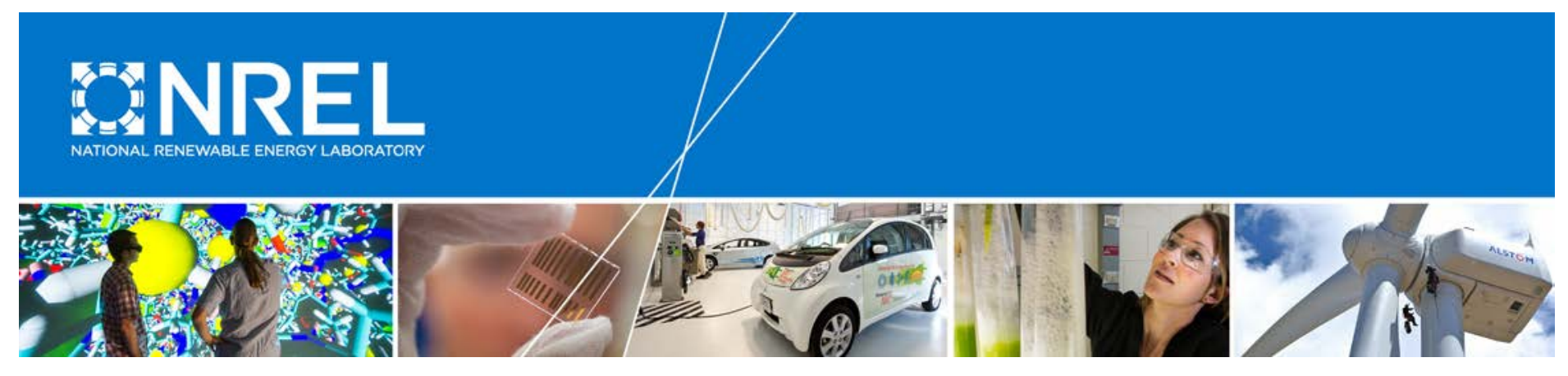

\title{
The DOE Next-Generation Drivetrain for Wind Turbine Applications: Gearbox, Generator, and Advanced Si/SiC Hybrid Inverter System
}

\section{Preprint}

\section{William Erdman}

Cinch, Inc.

Jonathan Keller

National Renewable Energy Laboratory

To be presented at the IEEE Energy Conversion Congress \& Exposition

Milwaukee, Wisconsin

September 18-22, 2016

(C) 2016 IEEE. Personal use of this material is permitted. Permission from IEEE must be obtained for all other uses, in any current or future media, including reprinting/republishing this material for advertising or promotional purposes, creating new collective works, for resale or redistribution to servers or lists, or reuse of any copyrighted component of this work in other works.

NREL is a national laboratory of the U.S. Department of Energy Office of Energy Efficiency \& Renewable Energy Operated by the Alliance for Sustainable Energy, LLC

This report is available at no cost from the National Renewable Energy Laboratory (NREL) at www.nrel.gov/publications.

\section{Conference Paper}

NREL/CP-5000-66562

August 2016

Contract No. DE-AC36-08G028308 


\section{NOTICE}

The submitted manuscript has been offered by an employee of the Alliance for Sustainable Energy, LLC (Alliance), a contractor of the US Government under Contract No. DE-AC36-08GO28308. Accordingly, the US Government and Alliance retain a nonexclusive royalty-free license to publish or reproduce the published form of this contribution, or allow others to do so, for US Government purposes.

This report was prepared as an account of work sponsored by an agency of the United States government. Neither the United States government nor any agency thereof, nor any of their employees, makes any warranty, express or implied, or assumes any legal liability or responsibility for the accuracy, completeness, or usefulness of any information, apparatus, product, or process disclosed, or represents that its use would not infringe privately owned rights. Reference herein to any specific commercial product, process, or service by trade name, trademark, manufacturer, or otherwise does not necessarily constitute or imply its endorsement, recommendation, or favoring by the United States government or any agency thereof. The views and opinions of authors expressed herein do not necessarily state or reflect those of the United States government or any agency thereof.

This report is available at no cost from the National Renewable Energy Laboratory (NREL) at www.nrel.gov/publications.

Available electronically at SciTech Connect http:/www.osti.gov/scitech

Available for a processing fee to U.S. Department of Energy and its contractors, in paper, from:

U.S. Department of Energy

Office of Scientific and Technical Information

P.O. Box 62

Oak Ridge, TN 37831-0062

OSTI http://www.osti.gov

Phone: 865.576.8401

Fax: 865.576.5728

Email: reports@osti.gov

Available for sale to the public, in paper, from:

U.S. Department of Commerce

National Technical Information Service

5301 Shawnee Road

Alexandria, VA 22312

NTIS http://www.ntis.gov

Phone: 800.553 .6847 or 703.605 .6000

Fax: 703.605.6900

Email: orders@ntis.gov 


\section{The DOE Next-Generation Drivetrain for Wind Turbine Applications: Gearbox, Generator, and Advanced Si/SiC Hybrid Inverter System}

\author{
William L. Erdman, Member, IEEE \\ Cinch, Inc. \\ Moraga, CA
}

\author{
Jonathan Keller \\ National Wind Technology Center \\ Golden, $\mathrm{CO}$ \\ jonathan.keller@nrel.gov
}

\begin{abstract}
This paper reports on the design and testing results from the U.S. Department of Energy Next-Generation Wind Turbine Drivetrain Project. The drivetrain design reduces the cost of energy by increasing energy capture through drivetrain efficiency improvements; by reducing operation and maintenance costs through reducing gearbox failures; and by lowering capital costs through weight reduction and a series of mechanical and electronic innovations. The paper provides an overview of the drivetrain gearbox and generator and provides a deeper look into the power converter system. The power converter has a number of innovations including the use of hybrid silicon (Si)/silicon carbide $(\mathrm{SiC})$ isolated baseplate switching modules. Switching energies are compared between $\mathrm{SiC}$ and $\mathrm{Si}$ PIN diodes. The efficiency improvement by use of the $\mathrm{SiC}$ diode in a three-level converter is also described. Finally, a brief discussion covering utility interconnect requirements for turbines is provided with a particular focus on utility events that lead to high transient torque loads on drivetrain mechanical elements.
\end{abstract}

Keywords-asynchronous generation; converter efficiency; cost of energy; drivetrain; FERC 661; frequency support; inverter efficiency; low-voltage ride-through negative sequence; mediumvoltage inverter; NERC utility interconnect; neutral point clamp (NPC); permanent magnet generator; SiC; silicon carbide; silicon PIN diode; wind energy

\section{INTRODUCTION}

For the past three decades, the U.S. Department of Energy (DOE) has been committed to reducing the cost of energy of U.S. wind-generation facilities. Fig. 1 represents the cost of energy progress that has been made through this time period [1]. In an effort to build on this progress, the second phase of the Next-Generation Drivetrain (NGD) Project was funded in 2012 with the National Renewable Energy Laboratory (NREL) taking the project lead. This project considered the megawatt (MW) class of utility-scale turbines ranging from 1.5-MW land-based machines to 10-MW offshore turbines. A unified turbine architecture across this spectrum of ratings, along with environmental and siting considerations, is provided in reference [1]. This reference also provides a method for quantifying the incremental value of a percentage point of drivetrain efficiency. The NGD project was intended to reduce the cost of energy in a threefold way: by increasing energy capture through significant drivetrain efficiency improvements; by reducing operation and maintenance costs predominately by reducing gearbox failures; and by lowering capital costs through weight reduction and a series of mechanical and electronic innovations. Additionally, utility interconnect requirements as dictated by FERC 661B and NERC PRC-0241 , as well as other regional transmission requirements, were to be factored into the design. Particular importance was placed on utility requirements that had the potential to provide high transient torque loading on the gearbox, which has been identified as a possible source of gearbox failures. The baseline drivetrain against which improvements are measured is that of a high-speed, typically six-pole "squirrel cage," or a doubly-fed induction generator utilizing a three-stage gearbox.

This paper will introduce the three major constituent elements of the NGD drivetrain including the gearbox, generator, and power electronic converter. The gearbox and generator will be summarized to understand their design features, innovations, and context within the NGD, while the power electronic converter will be discussed with an emphasis on the application of $4500 \mathrm{~V}$, isolated baseplate, hybrid modules utilizing silicon (Si) insulated-gate bipolar transistors (IGBTs) with silicon carbide (SiC) freewheeling barrier diodes. In discussing the power electronic converter, the contents herein should be considered as companion to papers [2] and [3], both of which include many important details of the inverter design. Recent test results demonstrating the improvement in inverter switching losses as a result of the $\mathrm{SiC}$ barrier diodes were completed in January 2016 and results are included herein.

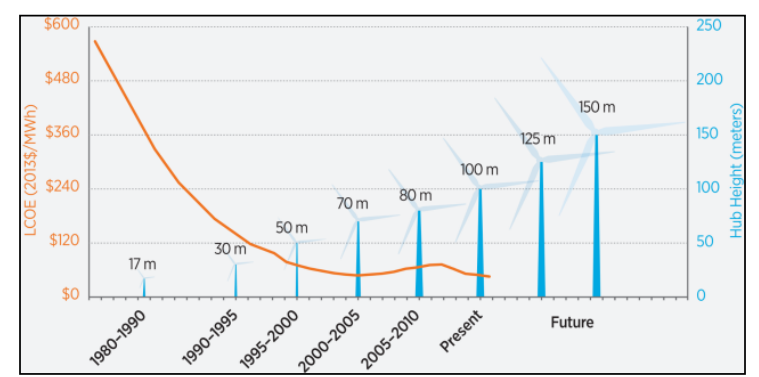

Fig. 1. Three-decade reduction in U.S. wind-generated cost of energy [1]. Chronology of typical rotor diameters and hub heights is also provided.

This project is funded by the U.S. Department of Energy through the U.S. Wind Power: Next Generation Drivetrain Development Funding Opportunity Announcement (DE-FOA-0000439). 


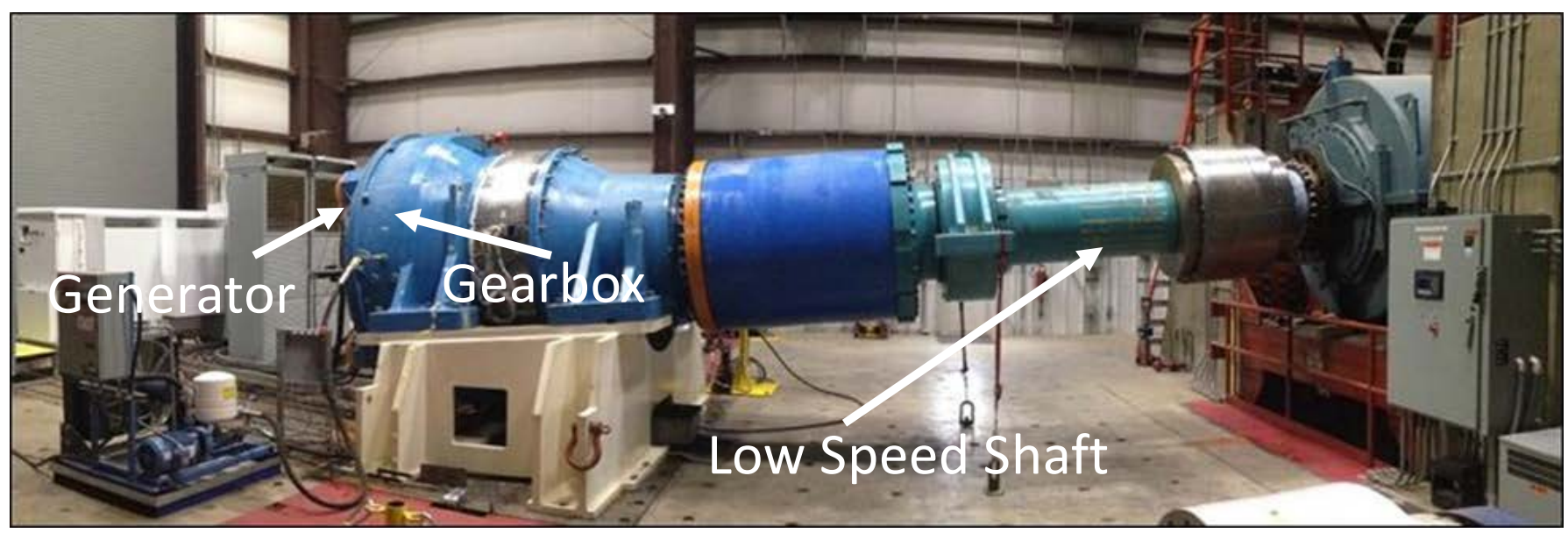

Fig. 2. Photograph of completed next-generation drivetrain during dynamometer testing. Photo by Jonathan Keller, NREL 35206

\section{NGD GEARBOX AND GENERATOR}

The integrated NGD gearbox and generator are summarized in this section, which describes how these components are configured in a typical turbine application. Important uptower operation and maintenance features, including service tooling, are also discussed. The NGD is shown in Fig. 2 as configured for dynamometer testing.

\section{A. Overview of Gearbox Design and Innovations}

The gearbox is a single-stage, epicyclic design with four planets and an overall ratio of 5.8:1, often termed as a "medium-" or "low-speed" gearbox. It is shown during assembly in Fig. 3. Standard rolling-element bearings on a rigid planet pin are replaced with hydrodynamic (journal) bearings

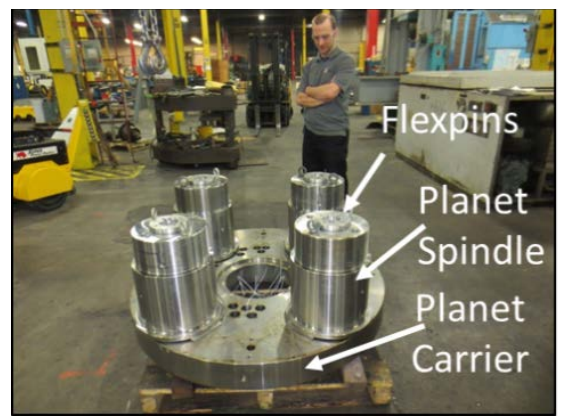

(a)

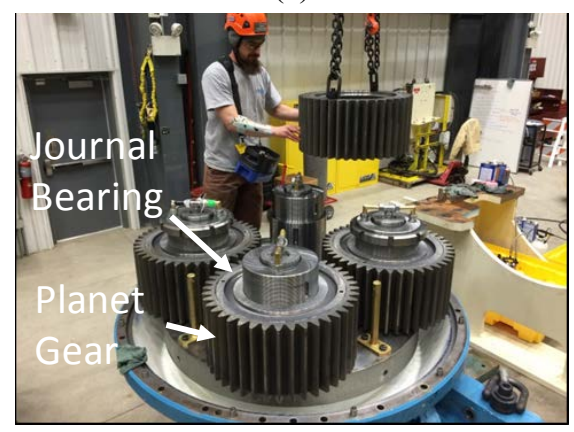

(b)

Fig. 3. (a) Planet carrier showing flexible pins and spindles; (b) planet gears and journal bearings supported by spindles. Photos by Chris Halse, NREL 33353, and Jonathan Keller, NREL 33341. on flexible pins for mounting of the planets. The flexible pins allow the loads to balance naturally between the planets reducing the size of the planetary stage, and the journal bearings reduce contact pressures eliminating a number of parts within the gearbox. Passages in the planet carrier and flex pins deliver the oil to the cavity between the spindle and journal bearing. The output torque from the gearbox is transmitted from the sun gear through a splined connection to the torque tube and generator rotor.

During the design process, flexible-pin deflections and stresses were analyzed as shown in Fig. 4. The design ensured von Mises stresses were within acceptable limits, including overload conditions. Additionally, locations of the flex pin strain measurements and journal bearing and oil supply temperature measurements are indicated. Not shown are ringgear strain measurements. Fig. 4 also demonstrates the loadsharing characteristics measured during dynamometer testing [4]. The loads become more balanced as the torque increases. At rated torque, there is less than $5 \%$ difference in the load carried by each planet.

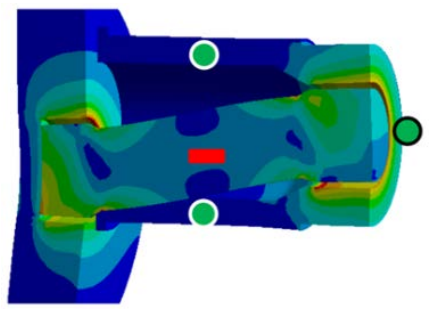

(a)
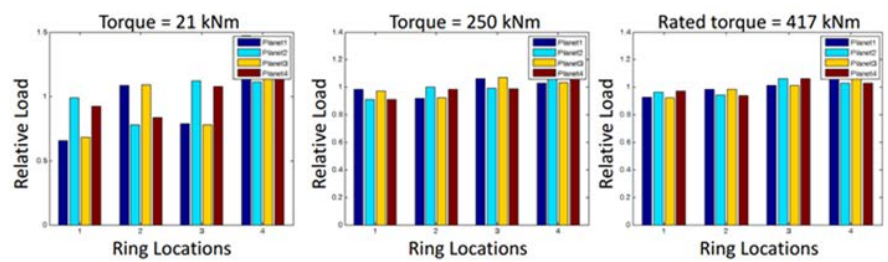

(b)

Fig. 4. (a) Flexible-pin von Mises stress analysis at rated torque (deflections are exaggerated for illustration); (b) flexible-pin load balancing characteristics at low, medium, and rated torque. Illustrations by Romax Technology. 
When compared to a traditional three-stage gearbox, this single-stage design increases the gearbox capacity through the multiple planets, flex pins, and journal bearings; and reliability by eliminating the more failure-prone intermediate- and highspeed gearbox stages. The elimination of two gearbox stages also increases gearbox efficiency.

\section{B. Overview of Low-Speed Surface Mount Permanent-Magnet Generator}

Consistent with the single-stage gearbox design, a lowspeed (not direct-drive) generator is required for operation at proper turbine rotor speeds. The low-speed, high-torque requirements of the generator necessitate a synchronous machine and lead to a relatively large diameter and weight when compared to that of the baseline high-speed generator. The larger generator places additional operation and maintenance requirements on the design leading to an uptower extractable rotor and a highly segmented, quick-disconnect stator and stator winding. The generator design facilitates uptower maintenance by means of special uptower maintenance tooling described herein. A unit-pole electromagnetic optimization of the machine was developed [5], which allows for speed, power, and pole-count scaling over the full $1.5-\mathrm{MW}$ to $10-\mathrm{MW}$ ratings. The unit-pole formulation is based on maintaining a predetermined per-unit reactance, which is different for active versus passive rectifier converter designs. A large range of turbine rotor diameters required for different wind regimes is also accommodated by the formulation. A detailed specification and design for a lowvoltage, 75 -kilonewton-meter $(\mathrm{kNm})$ generator is available in the NREL documents [5]-[7], with a subset of important specifications given in Table I.

TABLE I. 75-KNM GENERATOR SALIENT FEATURES

\begin{tabular}{|l|l|}
\hline Rated torque & $75 \mathrm{kNm}$ \\
\hline Airgap diameter & $1740 \mathrm{millimeter}(\mathrm{mm})$ \\
\hline Stack length & $350 \mathrm{~mm}$ \\
\hline Torque/rotor volume & $90 \mathrm{kNm} / \mathrm{m}^{3}$ \\
Shear stress & $6.5 \mathrm{PSI}$ \\
\hline Stator tooth & 72 stator teeth $(12$ segments), \\
Rotor-pole count & 48 rotor poles \\
\hline Stator winding & 8 turn, 24 series connected \\
& concentrated coils, edge wound \\
\hline Synchronous reactance & $0.33 \mathrm{PU}, \mathrm{X}_{\mathrm{D}}=0.9 \mathrm{X}_{\mathrm{Q}}$ \\
\hline Insulation system & $\mathrm{Class} \mathrm{H}, 180^{\circ} \mathrm{C}$ system \\
\hline $\begin{array}{l}\text { Magnet specification } \\
\text { Pole pitch \% }\end{array}$ & $\begin{array}{l}\text { ShinEtsu } \mathrm{N} 50 \mathrm{M} \\
85 \%\end{array}$ \\
\hline Phase resistance & $4.6 \mathrm{~m} \Omega$ at $150^{\circ} \mathrm{C}$ \\
\hline $\begin{array}{l}\text { Enclosure and cooling } \\
\text { approach }\end{array}$ & $\begin{array}{l}\text { Totally enclosed, liquid-cooled, } \\
\text { internal heat exchanger }\end{array}$ \\
\hline $\begin{array}{l}\text { Temperature rise } \\
\text { (during test) }\end{array}$ & $\begin{array}{l}150^{\circ} \mathrm{C} \text { stator with passive } \\
\text { rectifier, } 90^{\circ} \mathrm{C} \text { magnet }\end{array}$ \\
\hline
\end{tabular}

Fig. 5(a) is a photograph of the $75-\mathrm{kNm}$ generator rotor with the back cover removed. Rotor back-iron, surfacemounted magnet, magnet pole cap, and edge-wound concentrated stator coil can also be clearly identified in Fig. 5(b). Fig. 6(a) is a rendition of an extracted rotor with protective-foam magnet blanket; while extracted, the rotor is resting on the uptower rotor extraction tool. In Fig. 6(b), a sixtooth stator segment is shown extracted from the stator and frame assembly. The concentrated stator winding connections are disconnected from an interconnect bus ring at the drive end of the generator. The edge-wound stator coil is also shown before potting and placement over the stator tooth. The generator efficiency was tested at $97 \%$ (rated power) while following a cubic power/speed curve [6]. The high-efficiency generator, together with low-loss single-stage gearbox and high-efficiency medium-voltage converter, adds significant energy capture and value to the drivetrain design [2].

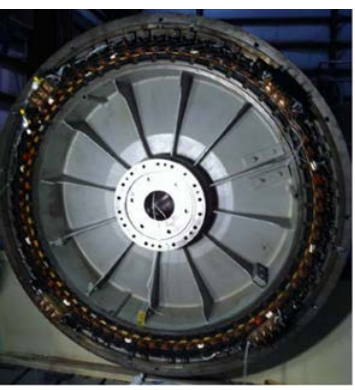

(a)

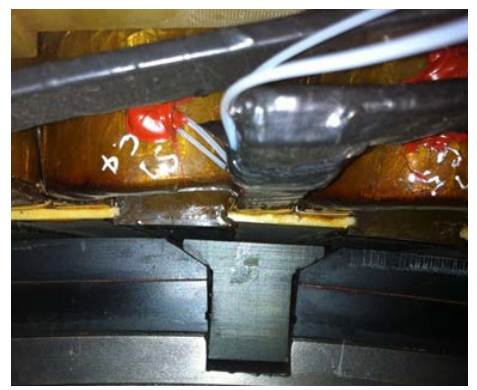

(b)
Fig. 5. (a) Photograph of completed generator showing rotor inserted in the stator assembly riding on the low-speed torque tube; (b) closeup of the generator airgap highlighting rotor and stator constituent elements. Photos by Jonathan Keller, NREL 33343 and 33345.

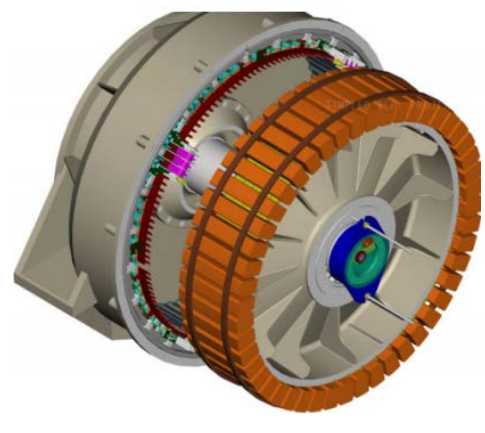

(a)

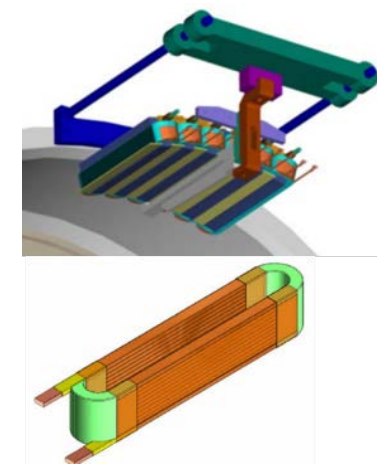

(b)
Fig. 6. (a) Extracted generator rotor; (b) extracted stator segment. Illustrations by Global Energy Concepts.

\section{NGD POWER-CONVERTER DESIGN}

The NGD power-converter design is based on the neutral point clamp (NPC), three-level architecture of Nabae [8] and is shown in Fig. 7(a). This converter approach has gained wide acceptance in medium-voltage power-conversion applications because of its effective use of semiconductor voltage ratings, superior harmonic content, and efficiency improvements as a result of semiconductor switching at one-half of the total DC bus voltage. The NGD design developed herein is intended to operate at $3.3 \mathrm{kV} \mathrm{AC}$ with a $+/-2.5 \mathrm{kV}$ DC (5000 VDC) bus voltage. The cost-of-energy benefits of medium-voltage apparatus in wind turbine architectures are covered in detail in reference [9]. For wind applications, the NPC architecture can be used back to back 
in a bidirectional, active rectifier configuration as shown in Fig. 7(b), or can be used in a unidirectional, passive rectifier configuration as shown in Fig. 7(c). A principal difference in these two configurations is the available speed range: a limitedspeed range is available in the unidirectional configuration, while an infinite-speed range is available in the bidirectional, activerectifier case. In either case, the NGD's fundamental NPC architecture utilizes a $4500-\mathrm{V}, 1200-\mathrm{A}$, isolated-baseplate $\mathrm{Si} / \mathrm{SiC}$ hybrid module selected to enhance the efficiency level of the NPC converter. This is done for energy capture and thermal management purposes [2]. The switching module utilizes a lategeneration 4500-V Si IGBT process and second-generation SiC Junction Barrier Schottky (JBS) diode to minimize switching losses. Use of the JBS diode is based on a desire to maximize the efficiency of the power converter. To fully understand the application of the JBS diode and the efficiency improvement, however, requires an understanding of the inverter's power factor during normal operation.

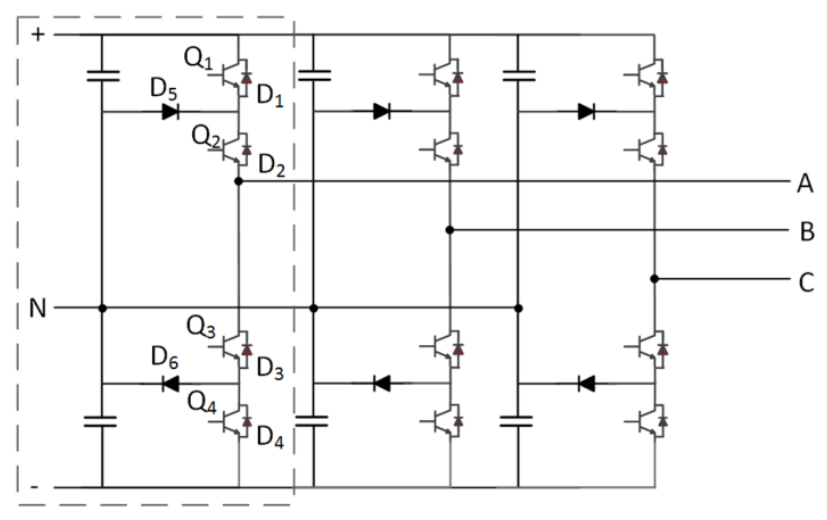

(a)

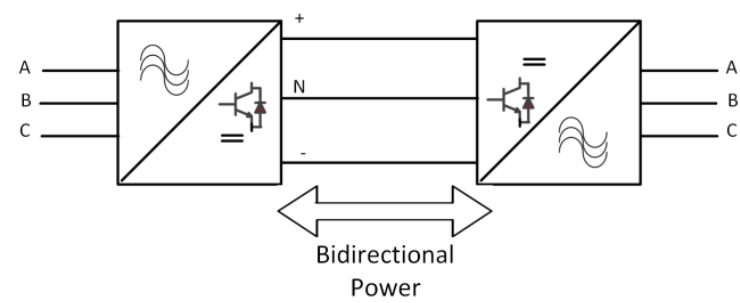

(b)

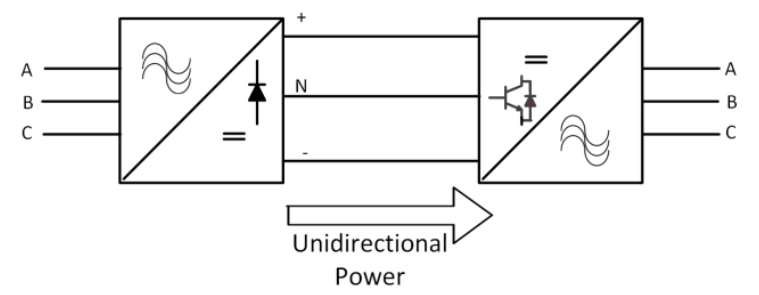

(c)

Fig. 7. (a) Schematic of the three-level neutral point clamp inverter with a single phase outlined that served as the $\mathrm{Si} / \mathrm{SiC}$ test fixture; (b) bidirectional infinite-speed range configuration used in a back-to-back configuration; (c) unidirectional, limited-speed range configuration applying a passive rectifier and neutral point clamp utility-connected inverter.

\section{A. Utility-Inverter Power-Factor Relationship and JBS Diode Location}

An important question arises when applying the JBS diode to the NPC converter. There are six diodes in each phase of the NPC circuit and, with a premium being paid for the JBS diode, in which location should such a diode be placed to maximize efficiency? The auxiliary switch locations Q2/D2 and Q3/D3 can be eliminated quickly, as these devices switch at the converter's fundamental frequency - a low-frequency and lowswitching loss condition. This leaves main switch diodes D1 and D4 and clamping diodes D5 and D6 as potential optimalefficiency locations. The selection between these two locations then comes down to the converter's operating power factor (PF). As it is common to specify the utility PF in renewableinterconnect inverter applications and not the inverter power factor, a PF relationship between utility and inverter is useful in informing the JBS diode location.

The simplified single-phase fundamental component, PU circuit of Fig. 8, is used to develop the PF relationship between inverter and utility. PU terms are as typically defined [10]. The utility voltage serves as the reference phasor and has no imaginary component. The inverter is shown as a current source to represent its instantaneous current-regulated control structure. Switching frequencies are assumed such that line filter reactances are in the range of 0.10 to $0.20 \mathrm{PU}$, to which transformer and other parasitic reactances can be added. When totaled, reactances dominate circuit resistance, which is ignored here.

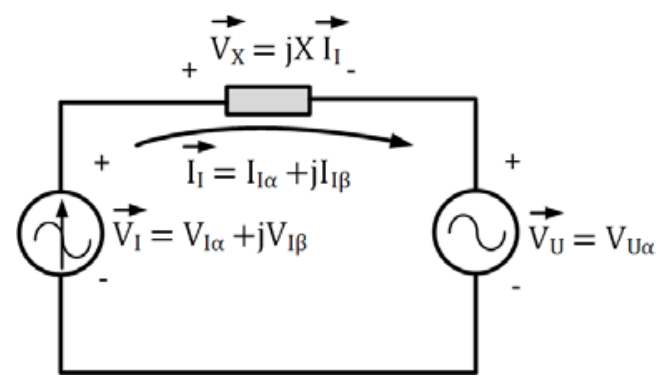

Fig. 8. Simplified single-phase representation of the inverter-utility circuit used to establish a (fundamental component) PF relationship.

A voltage loop equation provides

$$
\overrightarrow{V_{I}}=\left(V_{U \alpha}-X I_{\beta}\right)+j X I_{\alpha}
$$

The inverter-current angle and utility-PF angle are identical and defined as

$$
\theta \stackrel{\text { def }}{=} \tan ^{-1}\left(I_{\beta} / I_{\alpha}\right) \approx\left(I_{\beta} / I_{\alpha}\right)
$$

From (1), the inverter-voltage angle is defined as

$$
\begin{array}{r}
\varphi \stackrel{\text { def }}{=} \tan ^{-1}\left(X I_{\alpha} /\left(V_{U \alpha}-X I_{\beta}\right)\right) \approx \\
\left(X I_{\alpha} /\left(V_{U \alpha}-X I_{\beta}\right)\right)
\end{array}
$$

In wind applications, the utility PF is typically restricted to the region of $0.95 \leq|\mathrm{PF}| \leq 1.0$ (see FERC 661B, paragraph $\mathrm{G}$ 
for example). This utility range corresponds to $\mathrm{PF}$ angles where the approximations in (2) and (3) are sufficiently accurate. The inverter PF angle corresponds to the difference between the inverter current and inverter voltage angle

$$
\delta=\theta-\varphi \approx-\left(X I_{\alpha} /\left(V_{U \alpha}-X I_{\beta}\right)\right)+\theta
$$

At 1.0 PU utility voltage, the range of reactances discussed, and the PF restricted values of $I_{b},\left(V_{u \alpha}-X I_{b}\right) \approx \mathrm{V}_{u \alpha}$ and

$$
\delta \approx-\left(X I_{\alpha} / V_{U \alpha}\right)+\theta
$$

This last expression establishes a linear approximation between the inverter PF angle, $\delta$, and the utility PF angle, $\theta$. A plot of this expression is shown in Fig. 9(a). High-utility PFs lead to high-inverter PFs. One particularly interesting point identified is where the inverter PF is unity. At this operating point, the NPC inverter supplies no reactive power and the NPC circuit can be viewed as two simple decoupled (positive and negative) DC chopper circuits. The simplified positive circuit is shown in Fig. 9(b), where the auxiliary switch Q2/D2 is represented by a conductor as the Q2 IGBT is in the conduction state through the interval considered. The positive, upper portion of the NPC circuit sources the positive-phase voltage and current and, identically, the negative portion of the circuit provides the negative portion of the phase waveforms. At this unity PF operating point, only the clamping diodes carry current and are switched, experiencing reverse-recovery events. The placement of the JBS diode in the clamping location, therefore, provides the largest improvement in inverter efficiency. As the inverter PF deviates modestly from this point, the main diodes, D1 and D4, pick up switching cycles, but at high PFs, this number of cycles remains small relative to the clamping diodes

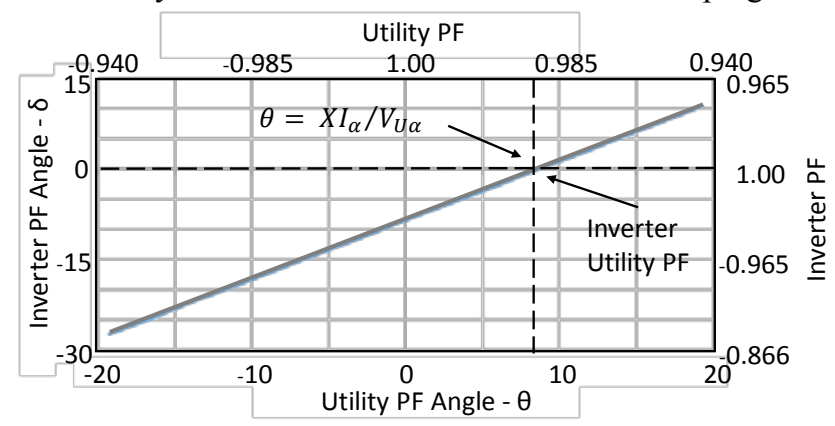

(a)

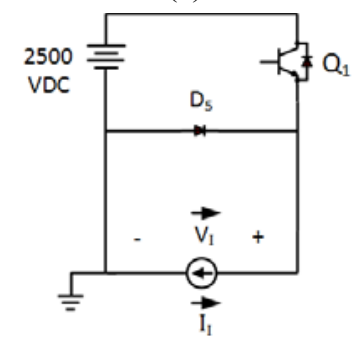

(b)

Fig. 9. Plot of inverter PF angle as a function of utility PF anglehigh-utility PFs lead to high-inverter PFs with typical PU reactances; (b) simplifed positive portion of the NPC inverterwhen operating at unity $\mathrm{PF}$, the symmetrical negative portion of the phase circuit operates during negative-phase voltage and current construction.
D5 and D6. In the limit, where $|\theta|=90^{\circ}$, or utility $\mathrm{PF}=0$, the number of switching cycles is equally split between the clamping and main diodes and maximum efficiency dictates placing a JBS diode in both locations to minimize switching losses.

\section{B. JBS Diode Performance}

An important innovation provided by the NGD project was the development of a hybrid 4500-V, 1200-A, Si-IGBT, SiCJBS diode in an isolated baseplate module. The module was packaged in the industrial standard $190 \mathrm{~mm} \times 140 \mathrm{~mm}$ form factor, allowing for simple substitution in existing $\mathrm{Si}$ inverter systems using this footprint. This also allowed easy interchanging of the standard Si module and hybrid module in the test fixture for qualification and comparison purposes. Module and chip descriptions, as well as details of the test fixture including laminated bus layout and measurement of bus parasitic impedances, are provided in references [2] and [3]. Because both modules applied identical IGBT generation structures, the test fixture focused on measuring diode-forward and reverse-biased conduction characteristics and on measuring IGBT and diode-switching energies. Conduction characteristics were tested early in the project and have been reported in references [2] and [3]. They are repeated in Fig. 10 for completeness. A comparison of diode-forward characteristics is shown in Fig. 10(a). Although the JBS diode has a higher forward-voltage drop, and therefore higher conduction losses, the total inverter conduction losses are small and the switching improvements in the JBS diode substantially make up for this small penalty. The reverse-bias current levels for the JBS diode at $125^{\circ} \mathrm{C}$ are shown in Fig. 10(b); these reverse currents were

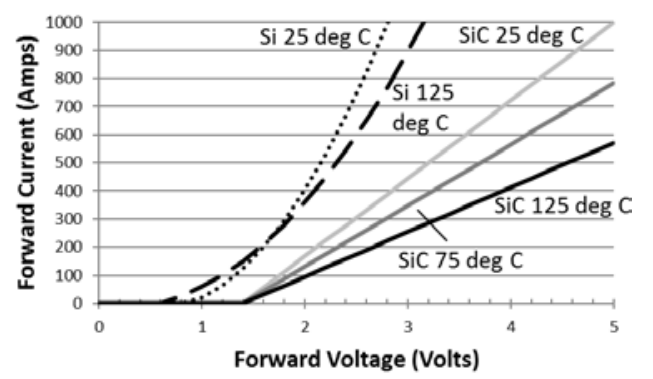

(a)

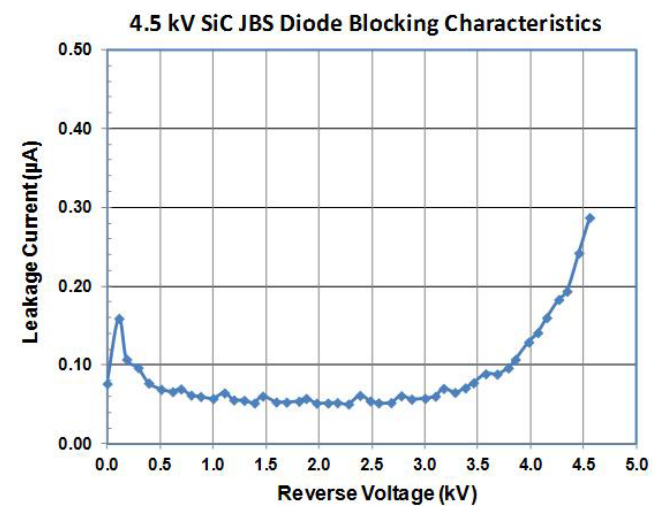

(b)

Fig. 10. (a) Forward-conduction charactersitics for the Si PIN and SiC JBS diode; (b) reverse-bias current levels for the 40-A chiplevel JBS diode. Illustration by Wolfspeed. 
taken at the chip level. An important characteristic of the unipolar JBS diode is that the reverse currents are predominately independent of junction temperature. Reversebias losses are extremely small relative to conduction and switching losses and are neglected in all inverter loss and efficiency calculations discussed.

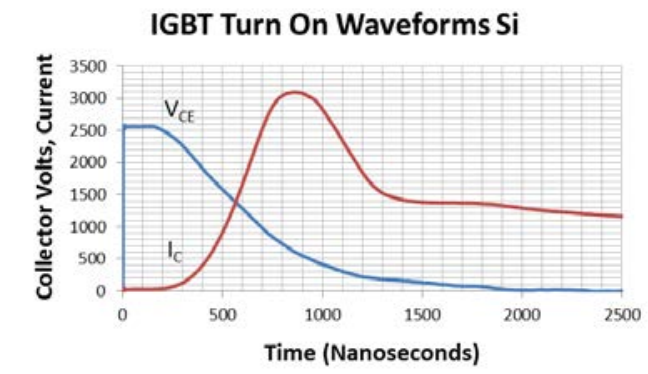

(a)

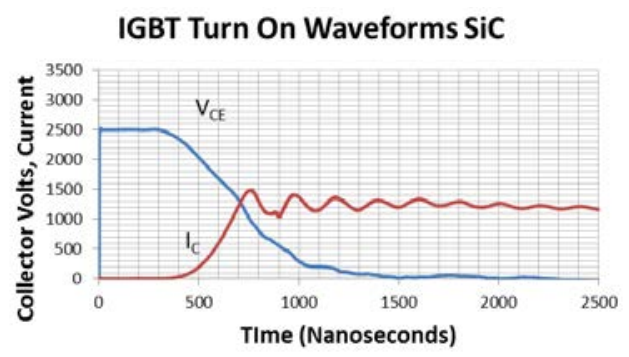

(b)

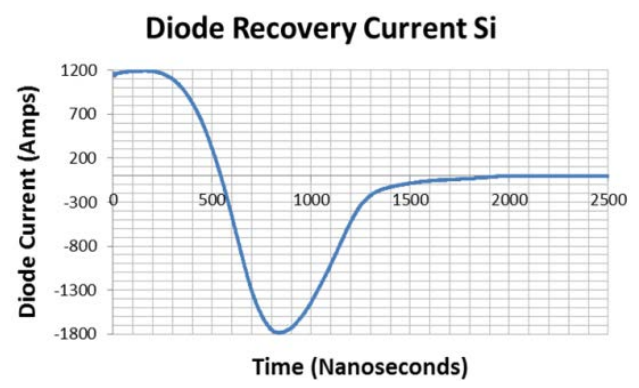

(c)

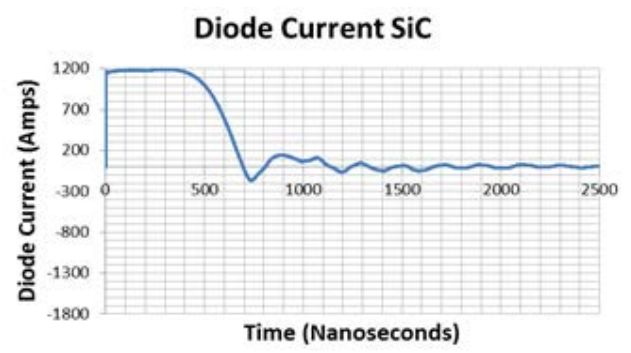

(d)

Fig. 11. IGBT turn-on characteristics are captured for (a) the $\mathrm{Si}$ PIN diode and (b) the SiC barrier diode. The elimination of the clamping-diode recovery current is apparent when comparing the two waveforms. Similarly, the diode-current switching characteristics are shown in (c) for the Si PIN diode and (d) for the $\mathrm{SiC}$ barrier diode. Again, the elimination of the diode reverserecovery current and the associated reduction in diode switching losses are apparent. All data taken at $\mathrm{V}_{\mathrm{CC}}=+/-2500 \mathrm{~V} \mathrm{DC}, \mathrm{V}_{\mathrm{ge}}=$ $+15 /-7 \mathrm{~V}, \mathrm{R}_{\text {gon }}=\mathrm{R}_{\text {goff }}=2 \mathrm{Ohms}$, and $\mathrm{T}_{\text {junction }}=115^{\circ} \mathrm{C}$ was taken from a full single-phase inverter test structure including all phaseparasitic elements.
Fig. 11 contains captured waveforms from dual-pulse switching tests in the full inverter test structure, including all laminated bus and incidental parasitic elements. Data was collected at a 4-nanosecond sampling rate on a 50-megahertz (MHz) oscilloscope. A 25-Mhz Rogowski coil served as the current sensor with special aperture designed to accommodate the large module terminations. High-voltage differential probes were used for voltage measurements. It can be seen that reverserecovery current is eliminated from the IGBT collector current during single-cell Q1 IGBT turn-on by comparing Fig. 11(a) and (b). Similarly, the reverse-recovery current is eliminated with the JBS diode switching waveforms in Fig. 11(d). These tests were performed at 200-A increments at full bus voltage of $\pm 2500 \mathrm{~V}$ DC. From these waveforms, switching energies were calculated and are reported in Fig. 12 [11]. Substantial energy improvements were found in IGBT turn-on conditions and in diode turn-off conditions. Use of the JBS diodes, however, does not affect IGBT turn-off energies, as can be seen in Fig. 12(c).

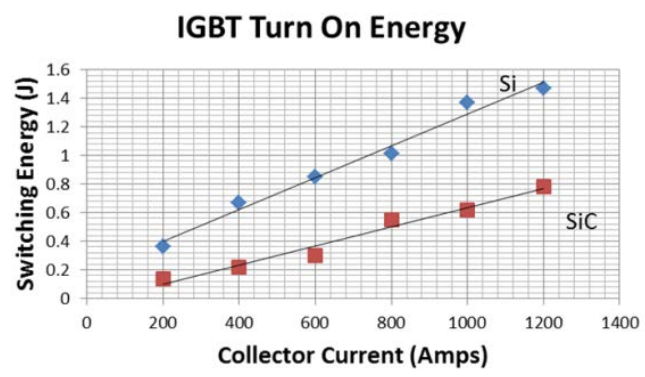

(a)

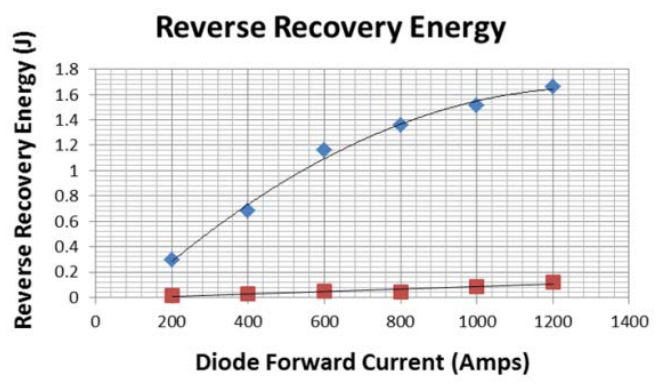

(b)

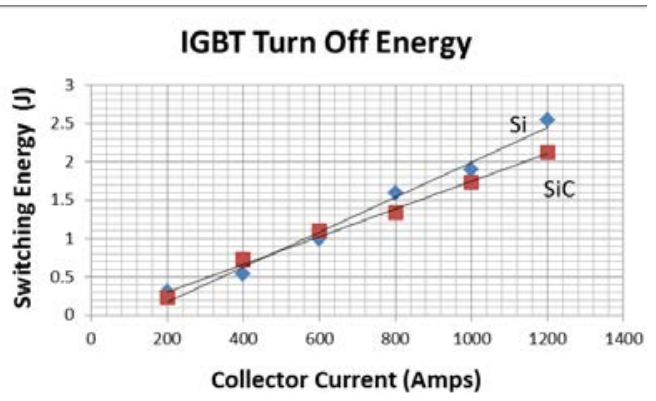

(c)

Fig. 12. (a) Single-cell Q1 IGBT switching energy as a function of collector current; (b) clamping diode D5 switching energy as a function of diode-forward current; (c) Q1 IGBT turn-off energy is not affected by the use of the JBS diode. 


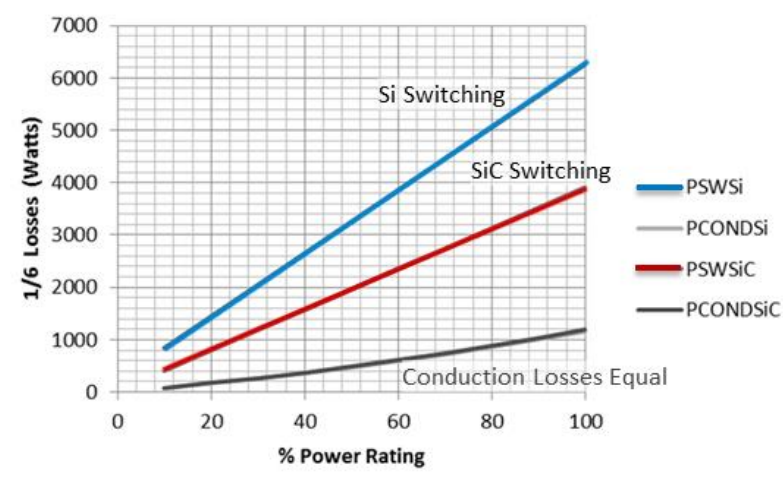

(a)

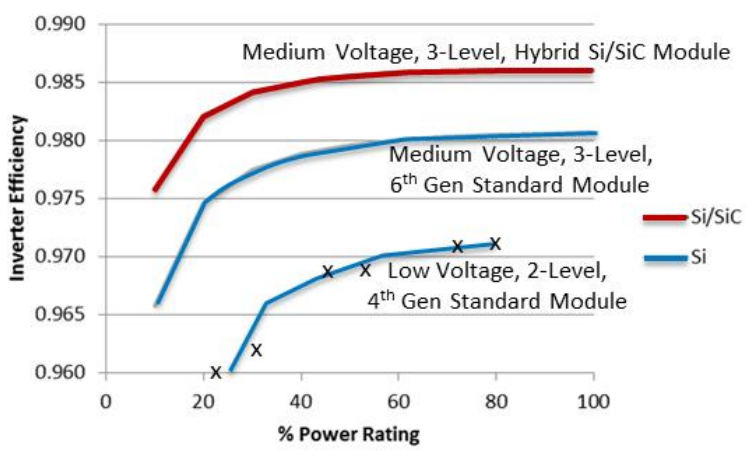

(b)

Fig. 13. (a) Switching and conduction loss comparison for a single cell (Q1/D1, Q2/D2, D5) in the three-level inverter with base current of $400 \mathrm{~A}_{\mathrm{RMS}}$. Note conduction losses are the same. (b) Computed efficiency for a three-level inverter with Si devices and with the hybrid $\mathrm{Si} / \mathrm{SiC}$ devices on a base $2.3 \mathrm{MW}$; the Xs identify data taken on a low-voltage, two-level inverter using a fourthgeneration Si IGBT/diode.

Using the switching energies from Fig. 12 and the forwardconduction characteristics from Fig. 10, inverter losses for a single cell and corresponding efficiency are computed [12] and are shown in Fig. 13(a) and (b), respectively.

\section{UTILITY INTERCONNECT REQUIREMENTS}

Renewable energy inverter designs must take into account highly evolving utility interconnect requirements. As the majority of wind turbines are being applied at utilitytransmission levels, distribution-level requirements such as California Rule 21 and UL 1741 are excluded from this discussion. The selected requirements for the inverter result from a thorough review of FERC 661-B, ERCOT requirements, NERC PRC-024, Hawaii, and Puerto Rico transmission-interconnect rules. A collated set of requirements was established by taking the most stringent requirement of each category of Fig. 14(a) from these various authorities [13]. Requirements are broken into three categories: Active Power Control, Reactive Power Control, and Disturbance RideThrough, as shown. These categories are broken down further into specific utility and operational conditions.
In addition to meeting the interconnect requirements from a power-system stability standpoint, the NGD project was specifically focused on requirements that were capable of causing high-transient torque conditions on the gearbox and drivetrain. Any condition that causes a significant change in real power is a potential candidate for large-torque transients. An example is shown in Fig. 14(b), where the drivetrain was subjected to two low-voltage ride-through events during dynamometer testing. The configuration used during the test included the passive rectifier with no drivetrain damping added. These tests were meant to duplicate field conditions that are believed to be contributing to gearbox failures. It can be seen that an immediate drop in utility voltage $(20 \%$ and $50 \%$ symmetrical faults) and then the recovery of the voltage corresponds to immediate changes in real power and torque disturbances. Upon the recovery of the utility voltage, real power and torque return; however, a severe torque transient on the drivetrain occurs. The oscillatory behavior following the disturbance is at the two-mass, compliant main shaft frequency. The dynamometer motor and the test generator inertias both reflected to the low-speed shaft with a compliant mainshaft between them. This is similar to a wind turbine application with large inertia rotor and generator inertia [14]. These types of transients must be considered in gearbox and drivetrain designs.

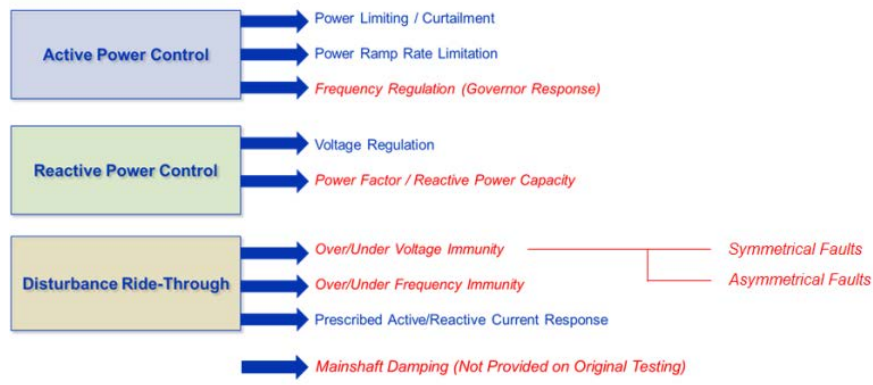

(a)

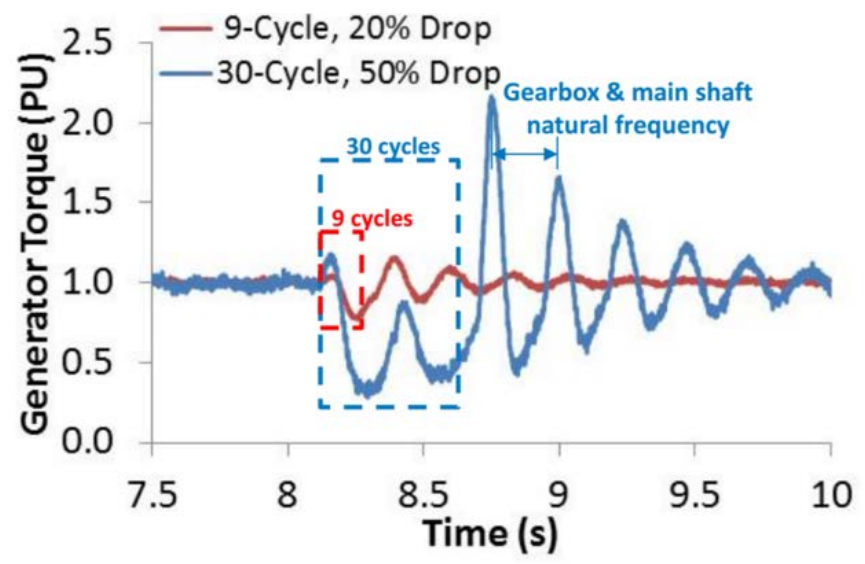

(b)

Fig. 14. (a) Classification of interconnect requirements into three categories; (b) dynamometer test data showing drivetrain torque transients resulting from low-voltage ride-through events. 


\section{CONCLUSIONS AND SUMMARY}

The DOE Next-Generation Drivetrain Project has resulted in a number of mechanical and electric/electronic innovations as presented in this paper. The simplified single-stage gearbox with flexible pins and journal bearings is intended to reduce gearbox failures that have plagued the wind energy industry. Test data have shown that the flexible pins are very effective in distributing gear-tooth load over all planets across a range of torque and speed levels. A model of the gearbox integrated with a low-speed permanent-magnet generator has also been developed, which can cover a wide turbine speed and power range with varying rotor diameters. A medium-voltage, threelevel NPC inverter has been applied in this drivetrain because of its efficiency advantages. The inverter efficiency is further enhanced by the application of hybrid, 4500-V Si-IGBT/SiC diode modules, leading to efficiency gains of $0.5 \%$ to $1.5 \%$. It has been shown that present interconnect requirements lead to a high-utility and inverter PFs, which leads to locating of the SiC diode in the clamping-diode location for best efficiency utilization. It has also been noted that NPC applications such as static VAR compensators, which operate at low PFs, requires replacing of clamping and main diodes for highest efficiency improvements.

\section{References}

[1] U.S. Department of Energy, "Wind Vision: A New Era for Wind Power in the United 2015. Available: http://energy.gov/sites/prod/files/2015/03/f20/wv_full_report. $\underline{\text { dff }}$

[2] W. Erdman, D. Grider, and E. VanBrunt, "4500 Volt Si/SiC Hybrid Module Qualification for Modern Megawatt Scale Wind Energy Inverters," Proceedings of the 2014 IEEE Wide Bandgap Power Semiconductor Workshop, Knoxville, TN.

[3] W. Erdman, J. Keller, D. Grider and E. VanBrunt, "A 2.3 MW Medium Voltage, Three-Level Wind Energy Inverter Applying Unique Bus Structure and 4.5 kV Si/SiC Hybrid Isolated Power Module," Proceedings of the 2015 Annual IEEE Applied Power Electronics and Application Conference, Charlotte, NC, p. 1282.

[4] J. Keller, W. Erdman, D. Blodgett, and C. Halse, "NREL Prime NextGeneration Drivetrain Dynamometer Test Report." NREL/TP-500066350, Golden, CO, National Renewable Energy Laboratory, 2016.

[5] R. Poore and T. Lettenmaier, "Alternative Design Study Report: WindPACT Advanced Wind Turbine Drive Train Designs Study," NREL Report No. NREL/SR-500-33196, Golden, CO, National Renewable Energy Laboratory, 2003.

[6] C. Walford, K. Lybarger, T. Lettenmaier, and D. Roberts, "Medium Speed Drivetrain Test Report," NREL Report No. NREL/SR-500051175, Golden, CO, National Renewable Energy Laboratory, 2012.

[7] T. Lettenmaier, W. Erdman, and D. Roberts, "WindPACT Generator Specification," Internal NREL Report, 2004.

[8] A. Nabae, I. Takahashi, and H. Akagi, "A New Neutral-Point-Clamped PWM Inverter," IEEE Transactions on Industry Applications, Vol IA17, NO. 5, Spetember/October, 1981.

[9] W. Erdman and M. Behnke, "Low Wind Speed Turbine Project Phase II: The Application of Medium-Voltage Electrical Apparatus to the Class of Variable Speed Multi-Megawatt Low Wind Speed Turbines," NREL Report No. NREL/SR-500-38686, Golden, CO, National Renewable Energy Laboratory, 2005.

[10] J. Grainger and W. Stevenson, "Power System Analysis," McGraw-Hill, Inc., 1994.

[11] A. Wintrich, U. Nicolai, W. Tursky, and T. Reimann, "Semikron Application Manual Power Semiconductors," Nuremberg, Germany, 2015. Available: $\quad$ https://www.semikron.com/dl/servicesupport/downloads/download/semikron-application-manual-power$\underline{\text { semiconductors-english-en-2015 }}$
[12] G. Tomta, "Analytical Equations for 3 Level NPC Converter Losses," in $9^{\text {th }}$ European Conference on Power Electronics and Applications, Graz, Austria, August 2001.

[13] D. Blodgett, M. Behnke, W. Erdman, "Power Converter Control Algorithm Design and Simulation for the NREL Next Generation Drivetrain," NREL internal report, Report No. NREL/SR-5000-66486, 2014.

[14] W. Erdman, "Control and Correlation of Mainshaft Torsional Modes on Wind Trubines and Off-Axis Loaded Dynamometers," American Wind Energy Association Annual Meeting, Las Vegas, NV, 2014. 